\title{
A comparison of East Antarctic sea-ice motion derived using drifting buoys and remote sensing
}

\author{
P. Heil ${ }^{1 *}$ C.W. Fowler, ${ }^{2}$ J. A. Maslanik, ${ }^{2}$ W. J. Emery, ${ }^{2}$ I. Allison ${ }^{1,3}$ \\ ${ }^{1}$ Antarctic CRC, University of Tasmania, Box 252-80, Hobart, Tasmania 7001, Australia \\ ${ }^{2}$ Colorado Center for Astrodynamics Research, Aerospace Engineering Sciences Department, \\ University of Colorado, Boulder, CO 80309-0431, U.S.A. \\ ${ }^{3}$ Australian Antarctic Division, Channel Highway, Kingston, Tasmania 7050, Australia
}

\begin{abstract}
Results of East Antarctic $\left(20-160^{\circ} \mathrm{E}\right)$ sea-ice motion derived from drifting buoys (collected in eight selected years between 1985 and 1997) are compared with sea-ice motion derived from sequential images from the 37 and $85.5 \mathrm{GHz}$ channels of the Scanning Multichannel Microwave Radiometer (SMMR, 1979-87) and the Special Sensor Microwave/Imager (SSM/I, 1987-97). For the latitudes of interest, buoys yield velocity fields at 2 hourly resolution, while SMMR and SSM/I provide daily data. The spatial coverage of the drifting buoys is relatively sparse compared to the complete coverage of the southern sea-ice zone by SMMR and SSM/I, but the accuracy of the buoy position is better than $\pm 280 \mathrm{~m}$, while the resolution for the $85.5 \mathrm{GHz}$ channel is only about $12.5 \mathrm{~km}$, and about $25 \mathrm{~km}$ for the $37 \mathrm{GHz}$ channel. The buoy measurements represent point motion, equal to the velocity of an individual ice floe, while the satellite data derived via the maximum cross-correlation method represent the motion of surface patterns within a gridcell. Comparison of the mean distributions of daily velocity derived from the datasets shows that while the broad-scale velocity patterns agree, the magnitude of the satellite-derived sea-ice velocities is significantly lower (typically by $40 \%$ or less) than the velocities derived from buoy measurements. This is in contrast with previous studies for the Arctic Ocean and the Weddell Sea, Antarctica. To elucidate differences in the velocity magnitude, individual trajectories from a number of drift regimes off East Antarctica are directly compared. Discrepancies between the two datasets are discussed with regard to the difference in spatial resolution of the data, the data-collection and -processing methods and the observed region.
\end{abstract}

\section{INTRODUGTION}

Sea ice and its movement within the polar seas are important components of the climate system. Sea-ice advection not only redistributes the pack, influences ice extent, concentration and thickness distribution, but also interacts with important components of the climate system such as surface albedo, oceanic density structure, or heat and moisture exchange at the ocean-atmosphere interface. Knowledge of sea-ice dynamics is necessary for full determination of the state of the sea-ice cover and its climatic interactions. With climate processes taking place on a large number of temporal and spatial scales, it is necessary to describe all components as completely and precisely as possible. Methods of observing sea-ice motion include in situ Lagrangian drifters as well as satellite-acquired images from optical, thermal, radar and passive-microwave instruments. Here sea-ice motion derived from buoy and satellite techniques is evaluated. Drifting buoys have been used for several decades, in both the Arctic (e.g. Thorndike and Colony, 1982) and Antarctic (e.g. Allison, 1989; Wadhams and others, 1989; Kottmeier and others, 1992)

\footnotetext{
* Present address: IARC/Frontier, University of Alaska Fairbanks, Fairbanks, AK 99775-7335, U.S.A.
}

to determine sea-ice motion. They offer high temporal and spatial resolution, but due to logistic restrictions buoys are not able to cover the sea-ice zone sufficiently.

Remotely sensed imagery from a number of satellite instruments (e.g. Scanning Multichannel Microwave Radiometer (SMMR), Special Sensor Microwave/Imager (SSM/ I), synthetic aperture radar (SAR) and Advanced Very High Resolution Radiometer (AVHRR)) have been investigated for the derivation of sea-ice velocity (e.g. Emery and others, 1991; Agnew and others, 1997; Kwok and others, 1998). With these the ice velocity is generally found from a sequential set of images, between which feature displacements are measured. Spatial and temporal resolution differ from sensor to sensor. While AVHRR provides data along a wide swath $(>1000 \mathrm{~km})$ at a resolution of approximately $1 \mathrm{~km}$, data are weather-dependent. SAR observations are largely weatherindependent, provide high-resolution data $(100 \mathrm{~m})$, but are available for a comparatively narrow swath, and at low temporal resolution only.

Emery and others (1997) demonstrated the usefulness of SSM/I data to obtain the mean circulation pattern of sea ice in the Arctic and Antarctic. SMMR (1979-87) and SSM/I data (1987 to present) provide a near-continuous record of daily ice velocities on a 25 and $12.5 \mathrm{~km}$ grid, respectively. Problems of the retrieval algorithm associated with surface wetness and atmospheric moisture can affect the $85.5 \mathrm{GHz}$ data (Emery and others, 1997), and motion fields derived 


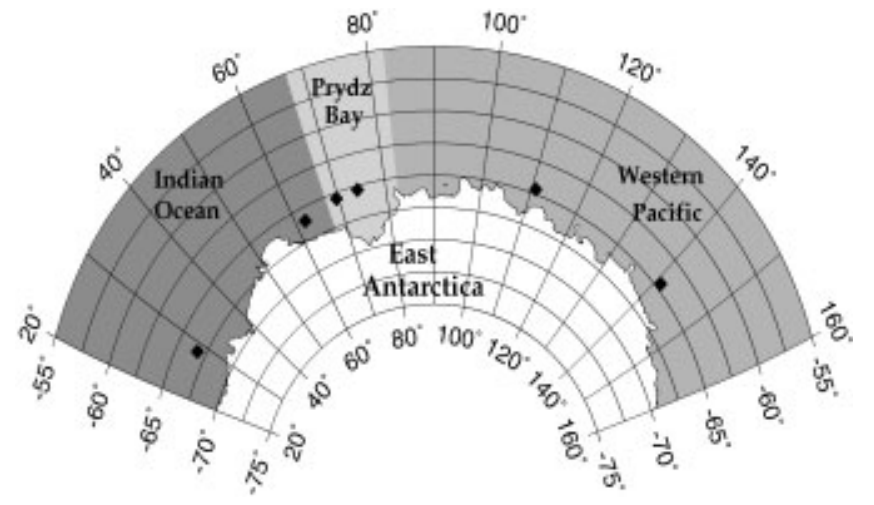

Fig. 1. Definition of sectors in the East Antarctic sea-ice zone, and initial positions (diamonds) of drifting buoys discussed in detail.

for autumn and winter appear most precise. Antarctic spring and summer data are thought to be less affected than Arctic data by the wetness problem, as surface melt in the Antarctic sea-ice zone is small compared to the Arctic. Snow wetness and saline percolation are believed to have a yearround effect on the surface appearance of the Antarctic sea ice. In this study, for the first time for the East Antarctic region, sea-ice motion fields derived from SMMR and $\mathrm{SSM} / \mathrm{I}$ are compared with buoy-derived sea-ice motion.

\section{MEASUREMENTS OF SEA-ICE MOTION}

Sea-ice motion is generally measured as the displacement of a tracer with time. Deploying expendable drifting buoys and following their motion with the sea ice represents the Lagrangian approach. Calculating displacement vectors from consecutive remotely sensed images over a defined grid yields the Eulerian sea-ice motion. The advantage of the latter lies in its wider coverage, which is presented on an even grid. However, both spatial and temporal resolution of the buoy-derived velocity field are better than for remotely sensed fields. High resolution is important, as only motion with a period longer than the sampling frequency and spatial scales larger than the spatial resolution of the instruments can be resolved.

\subsection{Buoy data}

Australian National Antarctic Research Expedition (ANARE) drifting-buoy data from the East Antarctic sector (20-160 E; Fig. 1) are available for eight years between 1985 and 1997. These buoy data have been analyzed extensively (Heil, 1999), and a climatology of the buoy-derived ice motion for the ice-covered zone around East Antarctica has been presented by Heil and Allison (1999). Buoy positions are generally derived via Doppler shift of a calibrated frequency signal (CLS Argos, 1990), although for the buoys used in 1995, position was determined with global positioning system (GPS) receivers. The spatial accuracy for the former is $\pm 280 \mathrm{~m}$ (Heil, 1999) and below $\pm 50 \mathrm{~m}$ for the latter.

ANARE buoys were generally deployed on sea-ice floes with typical thickness of about $0.6 \mathrm{~m}$. Floe sizes varied but generally exceeded a diameter of $50 \mathrm{~m}$. From direct comparison of the drift of seven GPS buoys (Heil, 1999) there is no evidence for an effect of floe size on the drift rate over the typical range of floe-size distribution off East Antarctica. Some of the early buoys were released within the newly forming sea ice during autumn. Visual observations confirmed that these buoys were quickly incorporated into the growing ice sheet. Measurements from temperature sensors were used to determine whether a buoy was enclosed by sea ice. Buoy specification and auxiliary instrumentation changed over time, but without effect on the measurements of the buoy position.

In the region of interest, buoy-derived positions are obtained about 18-25 times per day. This is sufficient for the sea-ice velocity field to be projected onto an even 2 hourly time grid. The accuracy for buoy-derived sea-ice velocity is $\pm 0.04 \mathrm{~m} \mathrm{~s}^{-1}$ for 2 hourly and $\pm 0.005 \mathrm{~m} \mathrm{~s}^{-1}$ for daily fields.

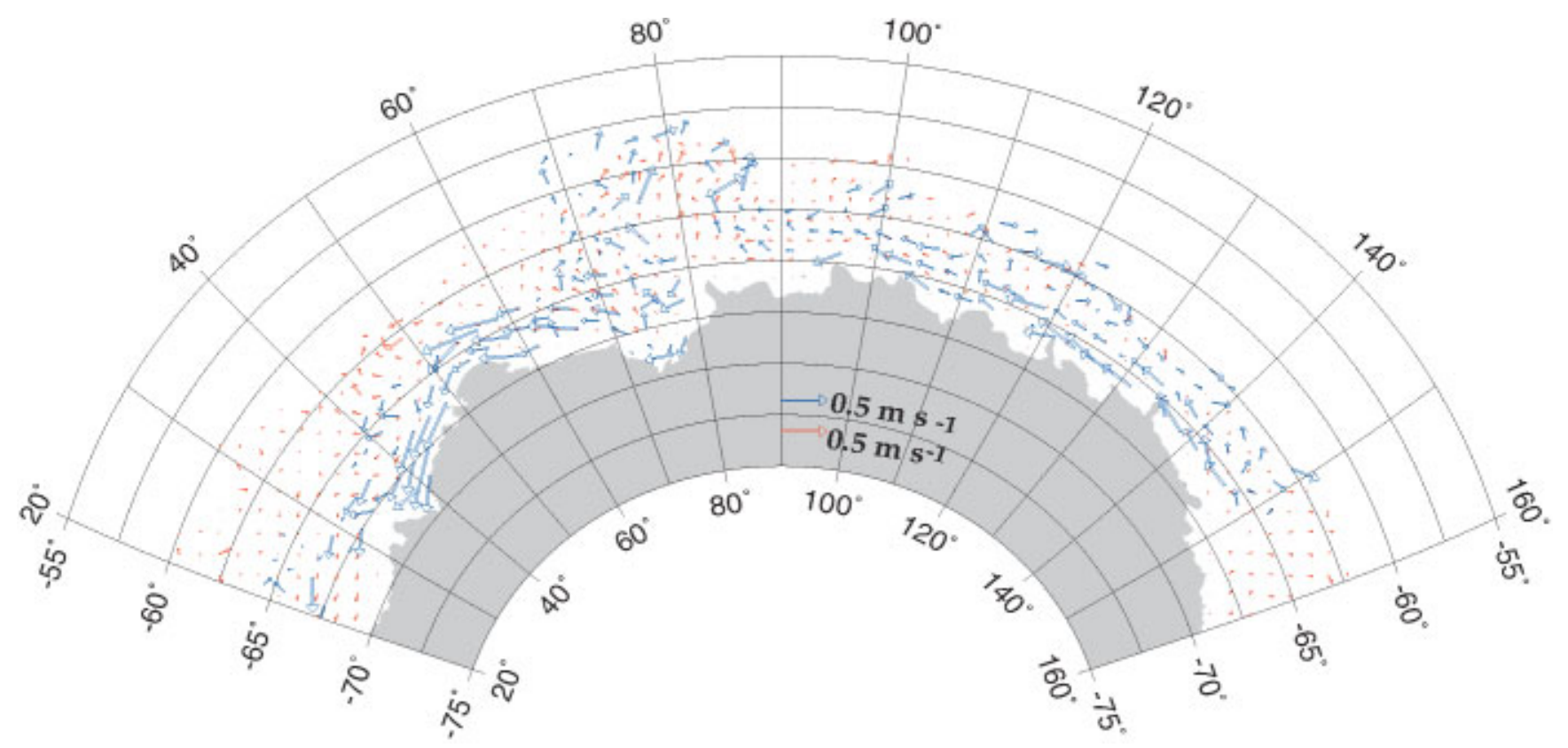

Fig. 2. The mean daily sea-ice velocity field as derived from the ANARE drifting buoys (blue). Mean daily sea-ice velocity for times matching buoy-data collection between 1987 and 1997 (red) derived from the 85.5 GHz channel of the SSM/I. 

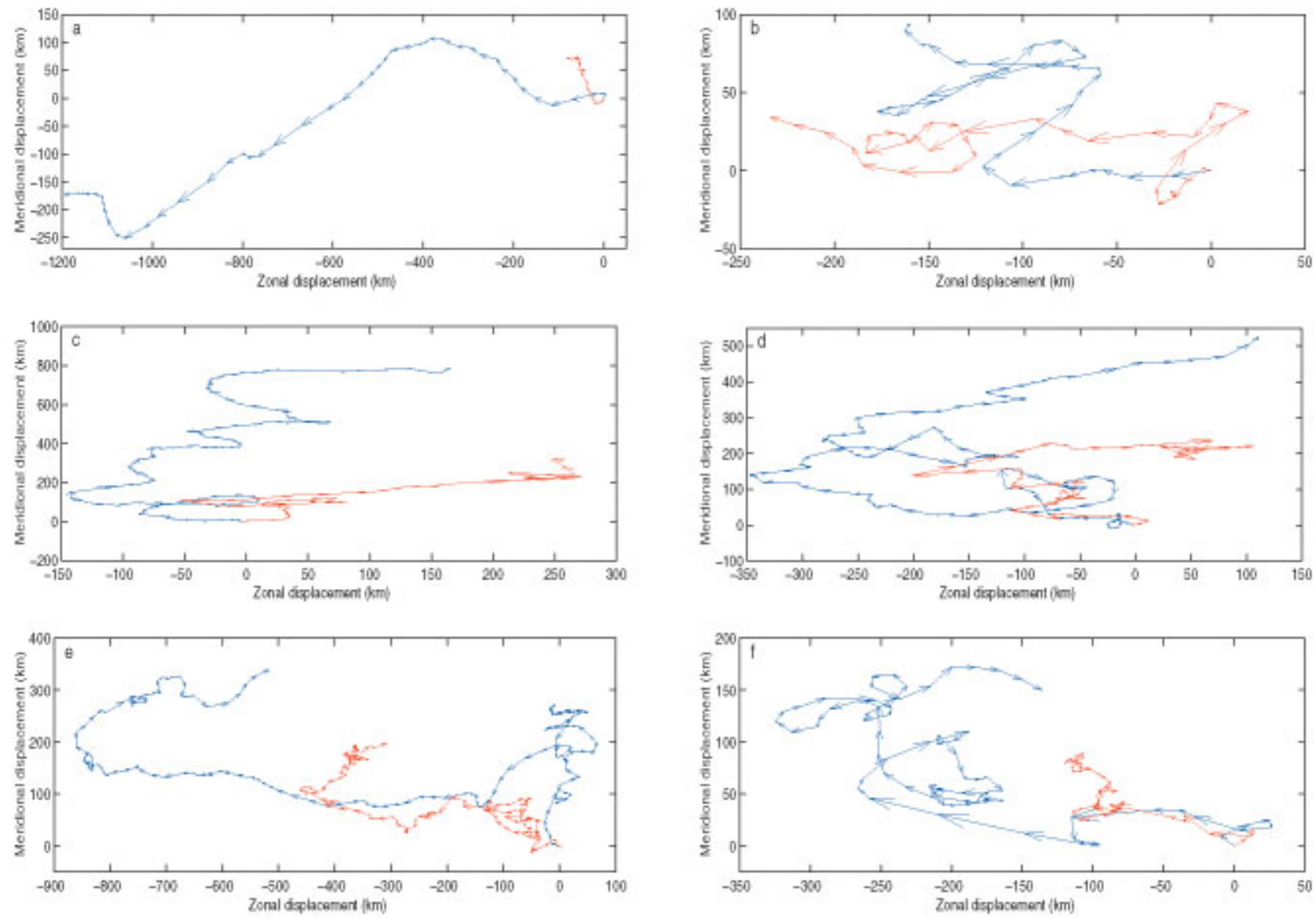

Fig. 3. Buoy-derived (blue) and satellite-derived (red) ice motion for several trajectors off East Antarctica. Dor, day ofyear. (a) Buoy AAD17 (Dor(1995) 89-137); ( b ) buoy AAD04 (DoY (1987) 190-231); (c) buoy AAD02 (Dor(1985) 63-213); (d) buoy AAD03 (DoY (1985) 72-213); (e) buoy AAD18 (DoY(1987) 116-292); (f) buoy AAD33 (Dor(1985) 229-311).

\subsection{Passive-microwave data from SMMR and SSM/I}

Gridded brightness temperatures from the $37 \mathrm{GHz}$ channel (SMMR and SSM/I) and the $85.5 \mathrm{GHz}$ channel (SSM/I) are available from the U.S. National Snow and Ice Data Center (NSIDC). Applying a maximum cross-correlation (MCG) method (Emery and others, 1991; Fowler, 1995; Agnew and others, 1997) these data are translated into displacement vectors of surface features, which are believed to represent the mean velocity field of the sea ice (Emery and others, 1997). The temporal resolution of these data is approximately $24 \mathrm{~h}$, with different locations of the sea-ice zone observed at different times of day. Sub-daily or smallscale motion cannot be detected from these data. The smallest translation that can be resolved is $3.4 \mathrm{~km}$, and daily motion slower than this cannot be detected. Slower motions, if persistent, could be derived from longer-term averages. Hence, the SMMR and SSM/I data have been used to calculate the large-scale and mean motion of the sea ice (e.g. Emery and others, 1997).

\section{ANALYSIS AND DISCUSSION}

Initially the mean daily ice drift within the region is discussed from both buoy- and satellite-derived data. To investigate differences in sea-ice velocity derived from these two datasets a comparison of the East Antarctic sea-ice motion is then carried out for regions with different motion characteristics. Following this the reproduction of mesoscale ice drift in the satellite-derived data is compared with GPS-derived buoy measurements.

\subsection{Overall comparison}

The mean distribution of daily sea-ice velocity was generated from all ANARE buoy data available between 1987 and 1997 (Fig. 2, blue). The mean velocity field derived from synchronous SSM/I data is shown in red (Fig. 2).

The overall correlation coefficient between the buoyand satellite-derived drift directions is 0.53 (based on a $100 \mathrm{~km} \times 100 \mathrm{~km}$ grid). The broad-scale drift patterns of the sea ice agree well. For example, both fields show a coastal current that varies in width with longitude; several northward paths of ice transport into the region of the eastward current; and some closed recirculation cells between the coastal current and the eastward-moving ice to the north. However, there are differences for some of the regional drift patterns. The correlation coefficient between the two datasets for the speed of drift is only 0.15 . Although both show broad differences in drift speed between the three sectors defined in Figure 1, for most regions the drift speeds differ markedly between the datasets. The drift speed derived from the satellite observations is consistently and significantly below the buoy-derived ice-drift speed.

\subsection{Regional analysis}

Direct and indirect observations (e.g. Tchernia and Jeannin, 1984; Heil and Allison, 1999) show that the sea-ice drift off East Antarctica is not uniform but exhibits regional characteristics. 

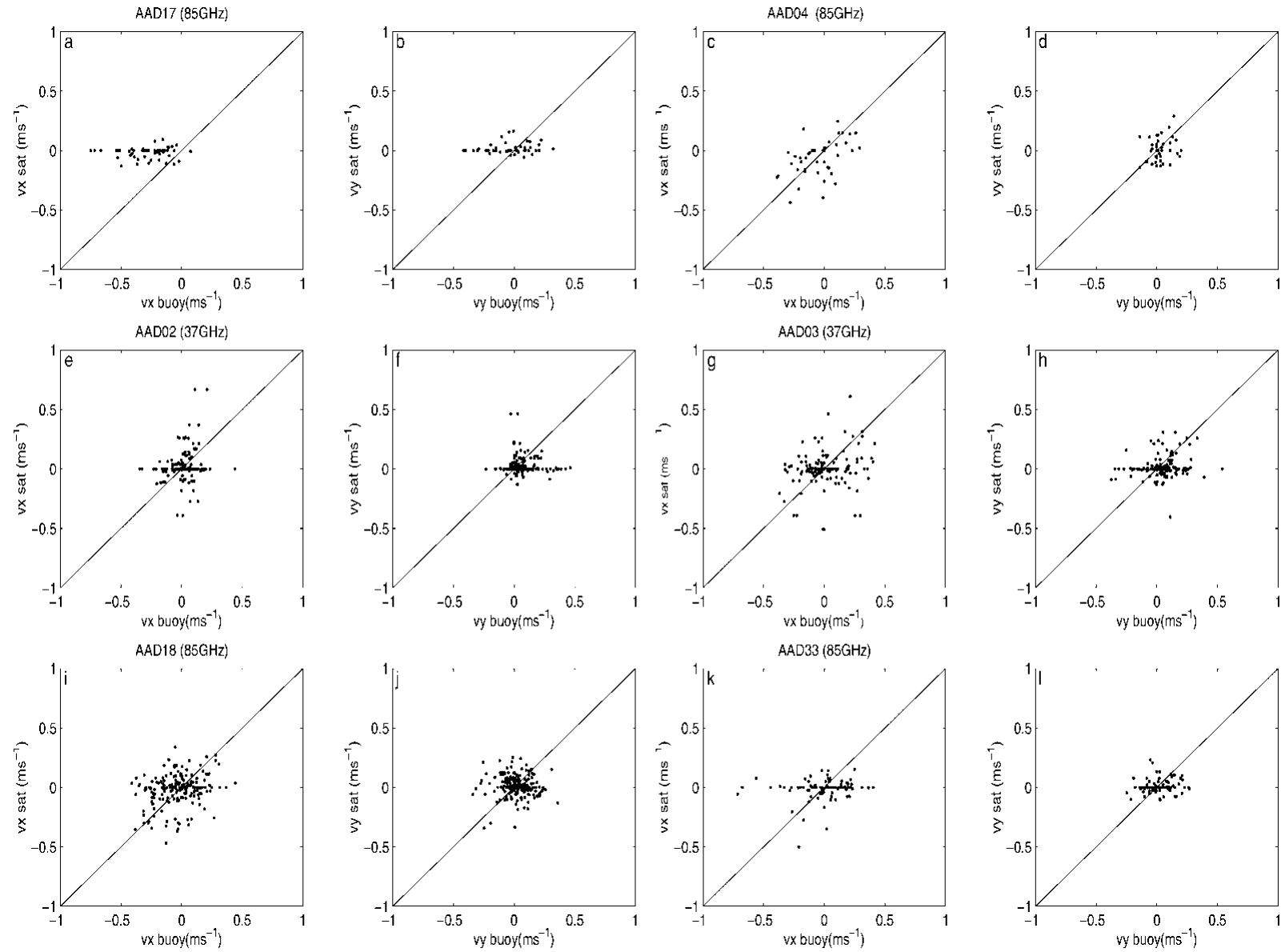

Fig. 4. Scatter plot of zonal and meridional velocity comparison for buoys $A A D 17(a, b), A A D 04(c, d), A A D 02(e, f), A A D 03$ $(g, h), A A D 18(i, j)$ and $A A D 33(k, l)$.

Here buoys from each of the three typical drift regimes off East Antarctica (marked by different grey shades in Fig. 1; Heil and Allison, 1999) are examined.

\section{Indian Ocean region $\left(20-67.5^{\circ} \mathrm{E}\right)$}

The sea-ice motion in this region is characterized by a high displacement rate and a low deformation rate. Fast westward movement along the continental slope is described by buoy AAD17 (Fig. 3a). This buoy was deployed on a floe within the newly forming ice in March 1995. Buoy AAD04 (Fig. 3b) describes ice motion near the continental shelf in the far western part of the sector during 1987. This area is dominated by convergence associated with the confluence of the local circulation around Maud Rise and the recirculation of the eastern branch of the Weddell Sea Gyre.

The comparison of satellite- and buoy-derived sea-ice velocity in the Indian Ocean sector shows that for drift dominated by high translation rates the satellite-derived velocities are significantly lower (in parts as low as 25\%) than measured by buoys. In the western part of the Indian Ocean sector both methods describe similar features for the trajectory of AAD04, although the satellite-derived speed is initially significantly slower than the buoy-derived speed. Both derived trajectories account for similar zonal translation. The scatter plots (Fig. 4c and d) of the comparison of zonal (correlation coefficient $R_{\mathrm{v} x}=0.48$ ) and meridional velocity $\left(R_{\mathrm{v} y}=0.73\right)$ components show a reasonable agreement for AAD04, the buoy travelling in the convergent regime. For both velocity components of AAD17, the scatter between buoy- and satellite-derived velocities flattens out towards high buoy speeds (Fig. 4a and b) due to the substantial underestimation of ice motion in the satellite-derived data. This is reflected in rather low correlation coefficients: $R_{\mathrm{v} x}=0.06$ and $R_{\mathrm{v} y}=0.23$.

\section{Prydz Bay region $\left(67.5-82.5^{\circ} \mathrm{E}\right)$}

Here a north-south divide is identified in the flow pattern. Within Prydz Bay itself the sea ice follows a cyclonic gyre, while to the north a powerful flow exports sea ice equatorward. This northward flow feeds into the large-scale cyclonic oceanic circulation extending around the Antarctic continent. Ice export is also identified in the northwestern edge of the Prydz Bay Gyre, where the gyre bifurcates and sea ice is expelled into the westward regime of the coastal Indian Ocean sector. The Prydz Bay sector is generally determined by divergent conditions. Overall ice motion in the Prydz Bay sector is slower than in the Indian Ocean sector (Heil and Allison, 1999).

Here we compare two datasets (AAD02 and AAD03) for ice motion observed in the northern part of the sector. Buoys deployed off the shelf within the Prydz Bay sector followed the net northward and later the net eastward motion of the ice (Fig. 3c and d). Off the shelf the meridional velocity component is dominant, resulting in an extreme northerly position of ice extent in the area around $80^{\circ} \mathrm{E}$. The comparison between buoy- and satellite-derived seaice velocity (Fig. 4e and $g$ for AAD02 and AAD03, respectively) shows that in this sector the zonal component of ice velocity for both methods is within the same range, although the satellite-derived one is smaller. The meridional 
Table 1. Examples from the mesoscale comparison of buoy-and satellite-derived ice velocity for August 1995 off East Antarctica. The magnitude of the mean speed $(|\vec{v}|)$ and the standard deviation $(\sigma)$ are shown

\begin{tabular}{ccccc}
\hline Cell & Number of buoys & $\begin{array}{c}\left|\vec{v}_{\text {Buoys }}\right| \\
\mathrm{m} \mathrm{s}^{-1}\end{array}$ & $\begin{array}{c}\sigma\left(\vec{v}_{\text {Buoys }}\right) \\
\mathrm{m} \mathrm{s}^{-1}\end{array}$ & $\begin{array}{c}\left|\vec{v}_{\text {sat }}\right| \\
\mathrm{m} \mathrm{s}^{-1}\end{array}$ \\
\hline 1 & 2 & 0.246 & \pm 0.009 & 0.134 \\
2 & 3 & 0.134 & \pm 0.050 & 0.056 \\
3 & 2 & 0.128 & \pm 0.053 & 0.014 \\
4 & 3 & 0.207 & \pm 0.049 & 0.093 \\
5 & 3 & 0.125 & \pm 0.028 & 0.090 \\
\hline
\end{tabular}

velocity derived from satellite observations is consistently less than the buoy-derived one (Fig. $4 \mathrm{f}$ and $\mathrm{h}$ ). The correlation coefficients here are low (AAD02: $R_{\mathrm{v} x}=0.17$ and $R_{\mathrm{v} y}=0.09 ;$ AAD03: $R_{\mathrm{v} x}=0.20$ and $\left.R_{\mathrm{v} y}=0.16\right)$.

In the southern Prydz Bay sector, where ice velocities are generally slower and where the meridional component of the sea-ice drift is dominant, the satellite-derived velocity field is not well resolved, and is generally significantly smaller than buoy-derived velocities (not shown here).

\section{Western Pacific region $\left(82.5-160^{\circ} \mathrm{E}\right)$}

Here, as in the Indian Ocean sector, motion is split into westward drift near the coast and eastward drift further north. The zonal velocity component is dominant. While in the Indian Ocean sector no exchange between westward and eastward ice flow has been observed, several northsouth-orientated transport channels between westward and eastward flow have been identified in the Western Pacific sector (Heil and Allison, 1999). These predominantly advect sea ice northward, although a few southward return channels have been identified.

In this sector the patterns of sea-ice velocity from the two datasets are in good agreement with each other (Fig. 3e and $\mathrm{f}$ for AAD18 and AAD33, respectively), but the magnitude of the satellite-derived ice speed is significantly underestimated, especially for the dominant velocity component. This is obvious in the comparison of the zonal components for the buoy- and satellite-derived ice motion (Fig. 4i and k). For buoy AAD 33 we find $R_{\mathrm{v} x}=0.14$ and $R_{\mathrm{v} y}=0.12$; for buoy AAD18 $R_{\mathrm{v} x}$ is 0.37 and $R_{\mathrm{v} y}$ is 0.46 .

\subsection{Mesoscale analysis}

To analyze the discrepancy between buoy- and satellitederived sea-ice velocity, mesoscale sea-ice motion and its variability are studied. In 1995, mesoscale ice motion was observed by seven GPS-equipped buoys deployed within the westward coastal current around $140^{\circ} \mathrm{E}, 65^{\circ} \mathrm{S}$, a region dominated by divergence. The motion of these buoys is used to study the mean sea-ice motion and its variability within an area covered by one gridcell of the SSM/I-derived velocity field. Often at least two buoys would be found within an area represented by one gridcell in the SSM/I data.

The velocity time series of the individual sea-ice buoys are very similar to each other. The drift is mainly determined by the moderate flow within the westward current. Changes in buoy velocity taking place at a time-scale of one to a few days are associated with atmospheric synoptic systems. The differ- ential motion within arrays of buoys shows that there is net divergence, although the signal is small.

The daily mean velocity of the satellite-derived motion was lower $(75 \%$ or less) than that derived from buoy data (Table 1). In the majority of cases for which two or more buoys drifted within the SSM/I footprint, even the mean velocity less standard deviation of buoy-derived motion was higher than the SSM/I-derived velocity. To resolve the difference we suggest as a working hypothesis that in divergencedominated regions the ice-motion patterns derived from the $\mathrm{SSM} / \mathrm{I}$ represent the propagation of surface features of the sea ice rather than the physical motion of individual morphological features such as floes, ridges or leads. The SSM/I may track aggregate characteristics of the ice pack within the satellite footprint, whereas buoys and higher-resolution data such as SAR track individual features such as floes or lead complexes within the pack. The analysis of this study and the deformation observed in the buoy arrays (e.g. Heil and others, 1998) show that there is continuous small- and mesoscale ice motion within the footprint of the $85.5 \mathrm{GHz} \mathrm{SSM} / \mathrm{I}$ field. At a gridcell size of $12.5 \mathrm{~km}$ by $12.5 \mathrm{~km}$, the $85.5 \mathrm{GHz}$ $\mathrm{SSM} / \mathrm{I}$ data cannot account for the motion of ice floes within the cell. We conclude that the drift of individual ice floes cannot be observed by the SMMR and SSM/I, and that the satellite-derived ice motion must be viewed as the propagation of the aggregate of surface features seen within the footprint rather than the translation of the sea ice itself.

\subsection{Discussion}

This comparison highlights the difficulties in mapping seaice velocities with a remote-sensing passive-microwave instrument. Velocity differences are most likely due to the large size of satellite-image pixels compared to the actual floe size, as well as to the associated problem of the feature detection based on brightness temperature. Additionally, inherent difficulties of high-frequency passive-microwave channels due to water vapour in the atmosphere (e.g. Massom and other, 1999) mask the detection of true ice velocity. As the East Antarctic pack is less concentrated than the pack in the Arctic or large parts of the Weddell Sea, the atmospheric moisture content above it is expected to be higher than for the Arctic or the Weddell Sea, and larger errors might be anticipated. The coarse spatial resolution of the passive-microwave imager acts as a spatial integrator to velocity signals within a gridbox. The size of individual ice floes is generally less than the footprint of the imager. This causes the derived velocity data to represent the motion of an aggregate of various types of ice floes and leads, rather than individual floes. Also, the ice-motion tracking from SMMR and SSM/I data might fail to identify features that are in rapid motion. Especially rapid differential motion, such as rotation or ridging and rafting, could result in a loss of tracking in these areas. Thus, the mean motion would be biased low. Lastly, the MCG method determines satellitederived sea-ice velocity as the translation of features, which consist of a number of individual pixels, over time. Hence the feature-tracking method by itself further reduces the spatial resolution. Results of this study have shown that it is crucial to determine the appropriate dimensions for the search and detection windows used by the MCG method. It was found that the size of the search window had been underestimated, and recalculated sea-ice velocities now contain some higher ice velocities. These findings lead us to interpret the differ- 
ence between buoy- and satellite-derived velocity as the difference between phase and group velocity. The buoy-derived velocity is similar to the phase velocity, and the satellitederived velocity is the group velocity. Additionally, due to the difficulties with the spatial integration near the land mask, the feature-tracking method cannot resolve the velocity distribution in coastal regions.

For completeness it is necessary to explore the effects of the chosen time-scale on the comparison of the sea-ice velocity data. Heil (1999) showed that the maximum velocity difference between daily and monthly data was $<0.05 \mathrm{~m} \mathrm{~s}^{-1}$ at very low ice concentration. This difference being less than the discrepancy between buoy- and passivemicrowave-derived sea-ice velocity shows that temporal variability at scales of 1 day or larger alone does not relate to the difference in ice velocity between buoy- and satellitederived motion.

\section{GONGLUSIONS}

Off East Antarctica the overall comparison between buoyand satellite-derived velocity fields for data from 1985 to 1997 shows that satellite-derived data are able to reproduce the broad-scale ice-drift pattern observed by buoys. The comparison between the two velocity fields identifies some substantial discrepancies between the two datasets. Typical satellite-derived drift speeds are $40 \%$ or less of the buoyderived speeds. To explain these differences we suggest that the buoy-derived ice-velocity field presents a detailed view on the physical motion of individual floes, whereas the satellite-derived field presents a velocity field for features of an aggregate of many sea-ice floes and classes, and possibly leads. Effectively the two methods measure velocities of two different properties, and due to the physical processes involved in translating these properties a total agreement between these two velocity fields cannot generally be expected.

This difference in velocity magnitude between buoy- and satellite-derived ice motion is in contrast with previous studies, which compared ice motion derived from passivemicrowave data with drifting-buoy data in the Arctic and in the Weddell Sea (e.g. Emery and others, 1997; Kwok and others, 1998). There a good agreement between the buoy- and satellite-derived magnitude of the velocity fields was found.

In the Arctic and also in the Weddell Sea the sea-ice dynamic and associated deformation processes differ considerably from those in unbound regions around East Antarctica. Drift rates in the Arctic and Weddell Sea are smaller and less variable than off East Antarctica. Convergence dominates the ice motion in the Arctic and large parts of the Weddell Sea, while off East Antarctica divergence prevails. The bound motion of sea ice in the Arctic and Weddell Sea causes the drift rates for individual ice floes in these regions to converge towards the drift rates of the slower large-scale features observed by the passive-microwave imagery.

It is important to consider this difference when using current passive-microwave-derived ice-velocity products for the initialization, calibration and verification of numerically modelled data fields. Care should be taken when verifying modelled data fields such as ice transport and volume flux with velocity derived from passive-microwave data. While monthly data appear useful in convergent regions (e.g. Drinkwater and others, 2001), it might be necessary to apply a corrective parameterization based on in situ observations in divergent regions in order to convert satellitederived data into sea-ice velocity. However, to improve the satellite-derived velocity dataset a re-analysis is currently underway. The ice-motion tracker has been modified, mainly to include a larger search area. Preliminary evaluation of these new data suggests a better agreement between buoy- and satellite-derived magnitude in ice velocity. Further improvement is expected from next generation passivemicrowave sensors to be launched on the Advanced Microwave Scanning Radiometer (AMSR) satellite, which will have double the spatial resolution.

\section{ACKNOWLEDGEMENTS}

The SMMR and SSM/I data were obtained from the Earth Observing System Distributed Active Archive Center at the NSIDC, Boulder, CO. P.H. thanks H. Enomoto (Kitami Institute of Technology, Japan) and R. A. Massom (Antarctic CRC, Australia) for discussions on the topic. The authors also thank the anonymous reviewers for their remarks.

\section{REFERENGES}

Agnew, T. A., H. Le and T. Hirose. 1997. Estimation of large-scale sea-ice motion from SSM/I 85.5 GHz imagery. Ann. Glaciol., 25, 305-311.

Allison, I. 1989. Pack-ice drift off East Antarctica and some implications. Ann. Glaciol., 12, 1-8.

CLS Argos. 1990. User manual. 1. Revised edition. Toulouse, CLS Argos.

Drinkwater, M. R., X. Liu and S. Harms. 2001. Combined satellite- and ULS-derived sea-ice flux in the Weddell Sea, Antarctica. Ann. Glaciol., 33 (see paper in this volume).

Emery, W. J., C.W. Fowler, J. Hawkins and R. H. Preller. 1991. Fram Strait satellite image-derived ice motions. 7. Geophys. Res., 96(C3), 4751-4768. (Correction: 7. Geophys. Res., 96(C5), 1991, 8917-8920.)

Emery, W. J., C.W. Fowler and J. A. Maslanik. 1997. Satellite-derived maps of Arctic and Antarctic sea-ice motion. Geophys. Res. Lett., 24(8), 897-900.

Fowler, C.W. 1995. Ice motion derived from satellite remote sensing with application to ice studies in the Beaufort Sea. (Ph.D. thesis, University of Colorado.

Heil, P. 1999. Sea-ice growth, drift and deformation off East Antarctica. (Ph.D. thesis, University of Tasmania.)

Heil, P. and I. Allison. 1999. The pattern and variability of Antarctic sea-ice drift in the Indian Ocean and western Pacific sector. 7. Geophys. Res., 104(C7), 15,789-15,802.

Heil, P., V. I. Lytle and I. Allison. 1998. Enhanced thermodynamic ice growth by sea-ice deformation. Ann. Glaciol., 27, 433-437.

Kottmeier, C., J. Olf, W. Frieden and R. Roth. 1992. Wind forcing and ice motion in the Weddell Sea region. F. Geophys. Res., 97(D18), 20,373-20,383.

Kwok, R., A. Schweiger, D. A. Rothrock, S. Pang and C. Kottmeier. 1998. Sea ice motion from satellite passive microwave imagery assessed with ERS SAR and buoy motions. F. Geophys. Res., 103(C4), 8191-8214.

Massom, R. A., J. C. Comiso, A. P. Worby, V. I. Lytle and L. Stock. 1999. Regional classes of sea ice cover in the East Antarctic pack observed from satellite and in situ data during a winter time period. Remote Sensing Environ., 68(1), 61-76.

Tchernia, P. and P. F. Jeannin. 1984. Circulation in Antarctic waters as revealed by iceberg tracks, 1972-1983. Polar Rec., 22(138), 263-269.

Thorndike, A. S. and R. Colony. 1982. Sea ice motion in response to geostrophic winds. 7. Geophys. Res., 87(C8), 5845-5852.

Wadhams, P., C. B. Sear, D. R. Crane, M. A. Rowe, S. J. Morrison and D.W. S. Limbert. 1989. Basin-scale ice motion and deformation in the Weddell Sea during winter. Ann. Glaciol., 12, 178-186. 